\title{
Frequency Control of Power System with Solar and Wind Power Stations by Using Frequency Band Control and Deadband Control of HVDC Interconnection Line
}

\author{
Kimiko Tada ${ }^{*}$, Takamasa Sato${ }^{1}$, Atsushi Umemura1, Rion Takahashi' ${ }^{1}$, Junji Tamura1, \\ Yoshiharu Matsumura' ${ }^{2}$, Tsukasa Taguchi², Akira Yamada ${ }^{2}$ \\ ${ }^{1}$ Department of Electrical and Electronic Engineering, Kitami Institute of Technology (KIT), Kitami, Japan \\ ${ }^{2}$ Hokkaido Electric Power Co., Inc., Sapporo, Japan \\ Email: ^m1752300105@std.kitami-it.ac.jp
}

How to cite this paper: Tada, K., Sato, T., Umemura, A., Takahashi, R., Tamura, J., Matsumura, Y., Taguchi, T. and Yamada, A. (2018) Frequency Control of Power System with Solar and Wind Power Stations by Using Frequency Band Control and Deadband Control of HVDC Interconnection Line. Journal of Power and Energy Engineering, 6, 48-63.

https://doi.org/10.4236/jpee.2018.69007

Received: August 22, 2018

Accepted: September 22, 2018

Published: September 25, 2018

Copyright (c) 2018 by authors and Scientific Research Publishing Inc. This work is licensed under the Creative Commons Attribution International License (CC BY 4.0).

http://creativecommons.org/licenses/by/4.0/

\section{(c) (i) Open Access}

\begin{abstract}
In recent years, environmental problems are becoming serious and renewable energy has attracted attention as their solutions. However, the electricity generation using the renewable energy has a demerit that the output becomes unstable because of intermittent characteristics, such as variations of wind speed or solar radiation intensity. Frequency fluctuations due to the installation of large scale wind farm (WF) and photovoltaics (PV) into the power system is a major concern. In order to solve the problem, this paper proposes two control methods using High Voltage Direct Current (HVDC) interconnection line to suppress the frequency fluctuations due to large scale of WF and PV. Comparative analysis between these two control methods is presented in this paper. One proposed method is a frequency control using a notch filter, and the other is using a deadband. Validity of the proposed methods is verified through simulation analyses, which is performed on a multi-machine power system model.
\end{abstract}

\section{Keywords}

High Voltage Direct Current (HVDC), System Frequency Control, PV Power Generation, Wind Power Generation, Notch Filter, Deadband

\section{Introduction}

Recently, global warming and depletion of fossil fuels have been becoming serious all over the world, and in Japan nuclear power plants have been stopped 
since the Great East Japan Earthquake that occurred in 2011. Therefore, from the viewpoint of securing energy security and improving environmental problems, renewable energy has been attracting. It is a theme that can greatly contribute to the revitalizations of industry and economic activities, and the improvement of people's lives. Among renewable energy power sources, wind power generation and solar power generation have been attracting. Wind power generation has the advantages of relatively low power generation cost and high energy conversion efficiency compared with other types of power generation using renewable energy. In solar power generation, there is an advantage that the power generation efficiency is almost constant irrespective of the size of the installation system, and noise is not generated during power generation. In fact, wind power generation and solar power generation have been increasing year by year, and the amount of wind power generation in the world of 2016 is about $486.7 \mathrm{GW}$ [1] and the amount of solar power generation is about $303 \mathrm{GW}$ [2]. The renewable energy is likely to continue increasing in the future. However, the power generation using such renewable energy system may cause frequency and voltage fluctuations in the power system because of their fluctuating output due to intermittent characteristics, such as variations of wind speed or solar radiation intensity. Based on this fact, the frequency fluctuations in the power system with renewable power sources have been suppressed by the frequency controls in the thermal power plants and the hydraulic power plants so far. However, if the renewable power sources will increase, it is expected that the frequency fluctuations could not be suppressed by those controls sufficiently. If the frequency fluctuations cannot be suppressed within the permissible range of power system frequency, it is possible that some power plants may be stopped and some electrical equipment cannot operate normally. In order to solve this problem, various methods have been investigated and reported. Among them, there have been many researches about application of battery system, however, the battery systems are, in general, very expensive due to installation cost etc. Therefore, in recent years, frequency control using HVDC transmission line instead of battery has been studied [3] [4] [5] [6] [7]. Although, in these references [3] [4] [5] [6] [7], various studies have been presented for frequency control by HVDC transmission line connecting an offshore wind farm and an onshore power system, there are few papers reporting frequency control using HVDC transmission line connecting two power systems [8] [9]. Reference [8] presents a control method to suppress the frequency fluctuations occurring due to a large amount of PV power generation and wind power generation, which is based on power flow control of HVDC interconnection line using a different type of deadband from those in this paper in its frequency control system. In this paper, two methods are proposed to suppress the frequency fluctuations in one power system installed with large PV power station and wind power station, which is based on power flow control of HVDC interconnection line. And, these two proposed methods are examined and compared through simulation analyses. 
One of the two methods is a frequency band control using a notch filter. Generally, frequency fluctuations in the power system are suppressed by frequency control of the synchronous generators. However, there is a frequency band in which the control performance is not sufficient. Therefore, by determining the frequency band in which the frequency adjustment ability decreases in the power system with renewable power sources installed, a notch filter capable of effectively extracting only this band can be designed. Then, using the designed notch filter, fluctuating power in that frequency band, which cannot be suppressed sufficiently in the power system with renewable power sources, is transmitted to another power system through the HVDC interconnection line. As a result, frequency fluctuations in the power system with renewable power sources are suppressed.

The other method is a frequency control using deadband. This control is very simple. Only when the frequency deviation in the power system with renewable power sources exceeds a threshold value, the frequency control of HVDC interconnection line activates and the fluctuating power is transmitted to another system. In the case of the frequency control using notch filter, the frequency control of HVDC transmission line is always in operation. However in the case of the frequency control using deadband, the frequency control of HVDC transmission line is in operation only when the frequency deviation exceeds the threshold value. Therefore fluctuations in the HVDC transmission line power in the latter case become smaller than those in the former case.

The effectiveness of the above two proposed methods is verified by simulation analysis executed on PSCAD/EMTDC software (4.2.1).

\section{Model System}

\subsection{Power System Model}

The power system model used in this study and its parameters are shown in Figure 1. It is a modified version of the IEEE standard model with 9 buses [10] which is composed of 3 synchronous generators (SG1, SG2, and SG3). SG1 and SG2 are thermal power plants (SG1: 300 MVA, SG2: 200 MVA), and SG3 is a hydraulic power plant (100 MVA). Moreover, a WF (40 MVA), a PV station (60 MVA), HVDC interconnection line (60MVA), and three loads (Loads A, B, and C) are connected to the main system [11]. Their conditions are shown in Table 1. The HVDC transmission line is connecting the main modified 9-bus power system (System A) and another large power system (infinite bus, System B) and the positive direction of its power flow is from System A to System B.

\subsection{Governor Model}

Governor is a device for controlling the rotational speed of the synchronous generator and turbine. When the balance between the turbine output and generator output does not hold, the rotational speed changes. In order to return the rotation speed to the synchronous speed, the turbine output is controlled by the 


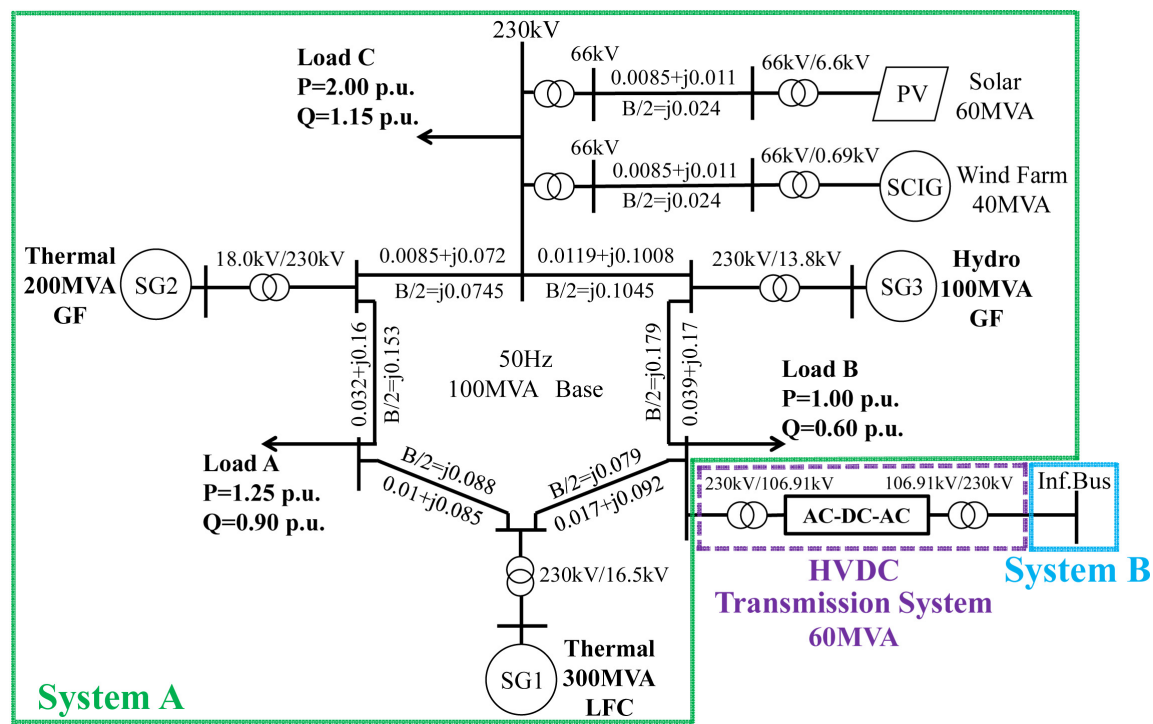

Figure 1. Model system.

Table 1. Conditions of each generator.

\begin{tabular}{cccc}
\hline & Generator & Rated MVA & Frequency Control \\
\hline SG1 & Thermal & $300 \mathrm{MVA}$ & LFC $^{\star 1}$ \\
SG2 & Thermal & $200 \mathrm{MVA}$ & $\mathrm{GF}^{* 2}$ \\
SG3 & Hydro & $100 \mathrm{MVA}$ & $\mathrm{GF}^{* 2}$ \\
SCIG & Wind Farm & $40 \mathrm{MVA}$ & \\
PV & Solar & $60 \mathrm{MVA}$ & \\
Total Load & & $480 \mathrm{MW}$ &
\end{tabular}

${ }^{* 1}$ LFC: Load Frequency Control, ${ }^{* 2}$ GF: Governor Free, ${ }^{* 3}$ SCIG: Squirrel Cage Induction Generator.

governor system. There are various frequency components in the power supplied to the power system from the wind generators and PV stations, resulting in frequency fluctuations of the power system. Conventional thermal and hydro governors control their turbine output to suppress the frequency fluctuations, in which short period components of from a few tens of seconds to a few minutes are controlled by the governor free (GF) operation and relatively long period components of from a few minutes to several tens of minutes are controlled by the load frequency control (LFC). These control blocks used in this paper are shown in Figure 2 and Figure 3 [12]. A hydraulic generator speed governor model used in the simulation analyses is shown in Figure 2, where

$S g$ : Rotation speed deviation

65M: Load setting (Output reference value)

77M: Load limit $(65 \mathrm{M}+$ rated output $\times$ PLM [\%])

PLM: Governor operating margin [\%] (A percentage of the rated output)

Pm: Turbine output

Input values of $65 \mathrm{M}$ and $77 \mathrm{M}$ are shown in Table 2. Thermal generator speed governor model and the LFC system model used in the simulation analyses are 


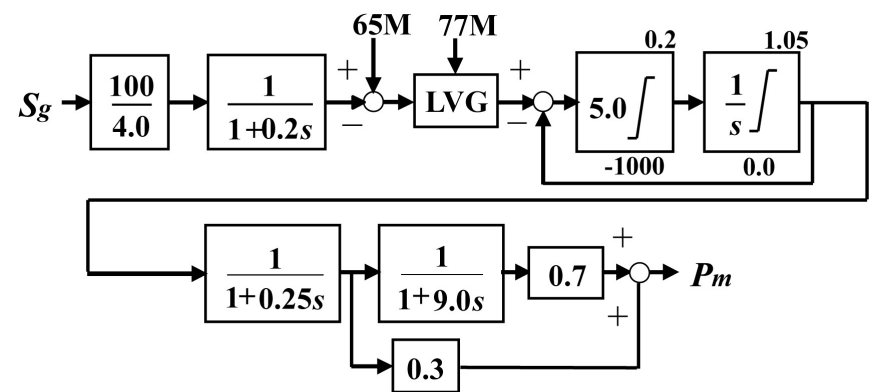

Figure 2. Hydro governor.

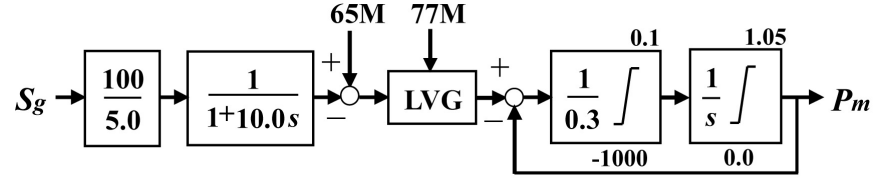

Figure 3. Thermal governor.

Table 2. $65 \mathrm{M}$ and $77 \mathrm{M}$ of each generator.

\begin{tabular}{ccc}
\hline & $65 \mathrm{M}$ (Load setting) & $\mathbf{7 7} \mathbf{M}$ (Load limit) \\
\hline SG1 & LFC Signal & LFC Signal + PLM \\
SG2 & 0.8 & 0.84 \\
SG3 & 0.8 & 0.84 \\
\hline
\end{tabular}

shown in Figure 3 and Figure 4. Load frequency control (LFC) supplies output command signal to the power plants according to the frequency deviation. The LFC signal is input to $65 \mathrm{M}$, and then, the output of each power plant is changed. The frequency deviation is input to the Low Pass Filter (LPF) to remove components of short period as shown in Figure 4, and then LFC signal is generated through PI controller. This is because the LFC is used to control frequency fluctuations with a long period of time. The angular frequency $\omega_{c}(=2 \pi f)$ of LPF is set to $0.005[\mathrm{~Hz}]$. The governor models used in this paper are based on the standard models of the Institute of Electrical Engineers of Japan.

\subsection{Wind Turbine Model}

Wind turbine model used in this paper is shown in Equations (1)-(5) [13].

$$
\begin{gathered}
P_{w t b}=(1 / 2) \rho C_{p}(\lambda, \beta) \pi R^{2} V_{w}^{3} \\
C_{p}(\lambda, \beta)=(1 / 2)\left(\Gamma-0.022 \beta^{2}-5.6\right) \mathrm{e}^{-0.17 \Gamma} \\
\lambda=\left(\omega_{W t b} R\right) / V_{w} \\
\Gamma=(R / \lambda)(3600 / 1609), \quad C_{t}(\lambda)=C_{p}(\lambda) / \lambda \\
\tau_{M}=(1 / 2) \rho C_{t}(\lambda) \pi R^{3} V_{w}^{2}
\end{gathered}
$$

where, $P_{w t b}:$ wind turbine output $[\mathrm{W}], \lambda$ : tip speed ratio, $R$ : wind turbine radius $[\mathrm{m}], \omega_{W t b}:$ wind turbine angular speed $[\mathrm{rad} / \mathrm{s}], \beta:$ pitch angle $[\mathrm{deg}], V_{w}:$ wind 


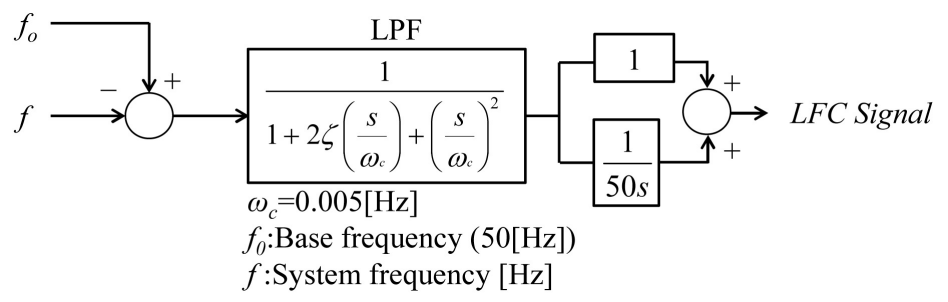

Figure 4. LFC system.

speed $[\mathrm{m} / \mathrm{s}], \rho$ : air density $\left[\mathrm{kg} / \mathrm{m}^{3}\right], C_{p}$ : power coefficient, $C_{\dot{t}}$ torque coefficient, $\tau_{M}$ : wind turbine torque $[\mathrm{Nm}]$.

\subsection{PV System}

PV model used in this study is shown in Figure 5 [8]. In this study, the PV model is expressed by a simple model using current sources, in which kilowatts data, $P_{P V}[\mathrm{~kW}]$, is used. Therefore, PV current $\left(I_{P V}\right)$ is calculated from $P_{P V}[\mathrm{~kW}]$ and $V_{P V}[\mathrm{kV}]$, and the obtained current $\left(I_{P V}\right)$ is entered to the grid from the current sources. PV voltage $\left(V_{P V}\right)$ is fixed at $6.6 \mathrm{kV}$.

\subsection{HVDC System}

The HVDC system model used in this study is shown in Figure 6 [7] [9]. In this study, to shorten the calculation time of the simulation, the HVDC model is expressed by the simple model [11] using controlled voltage sources instead of IGBT based inverter and rectifier.

\subsubsection{Control Model of System Aa Side Converter}

The control block of the converter that converts from three-phase AC to DC voltage is designed as shown in Figure 7. First, the phase angle is obtained by detecting the phase voltage $V_{r}$ from the three-phase terminal voltage at the converter. Next, the d-axis and q-axis components $\left(I_{r d} I_{r q}\right)$ of the current are obtained from the phase angle and the three-phase current. Active power $P_{r}$ and reactive power $Q_{r}$ of the converter are controlled independently by the d-axis and the q-axis components. For this purpose, the d-axis and q-axis components $\left(V_{r d}^{*}, V_{r q}^{*}\right)$ of the voltage are obtained through the PI controller. An output reference value $P_{r e f}$ is determined so as to suppress system frequency fluctuations (described later). Finally, the $\mathrm{d}$-axis and $\mathrm{q}$-axis voltages are converted to three-phase AC voltages. The parameters of PI controllers (PI1, PI2) are shown in Table 3.

\subsubsection{Control Model of System B Side Inverter}

The control block of the inverter that converts the DC voltage to the three-phase AC is designed as shown in Figure 8. As shown in Figure 8, the phase angle is obtained by detecting the phase voltage $V_{q}$ from the three-phase terminal voltage at the inverter. Next, the d-axis and q-axis components $\left(I_{q d} I_{q q}\right)$ of the current are obtained from the phase angle and the three-phase current. DC voltage $V_{d c}$ 


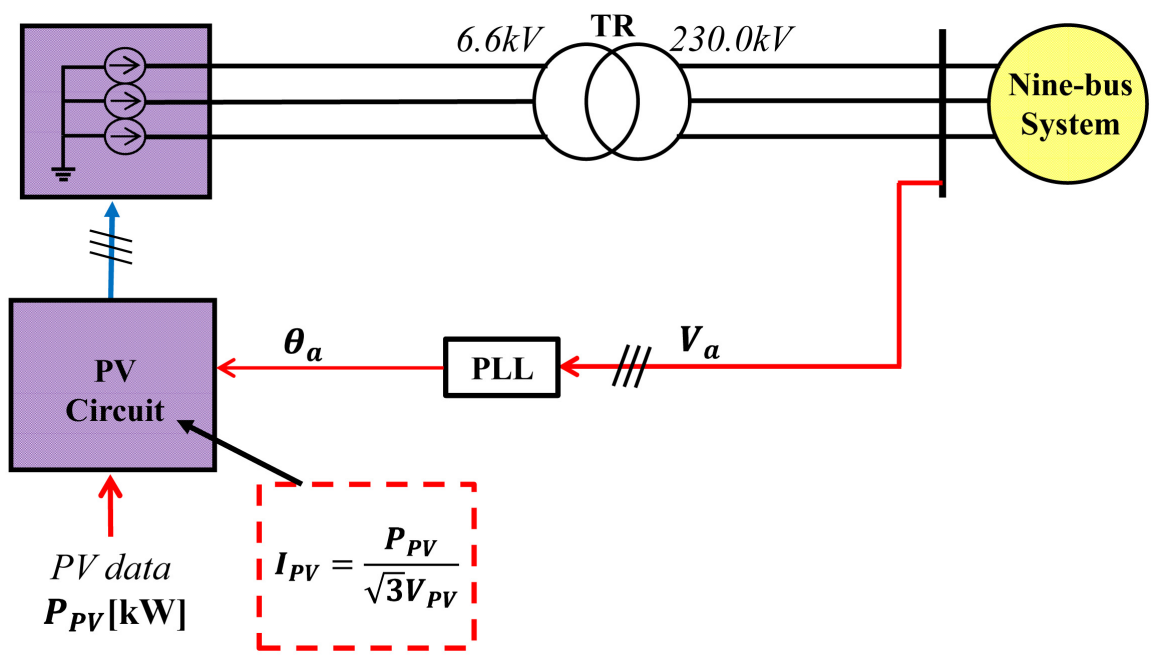

Figure 5. PV model.

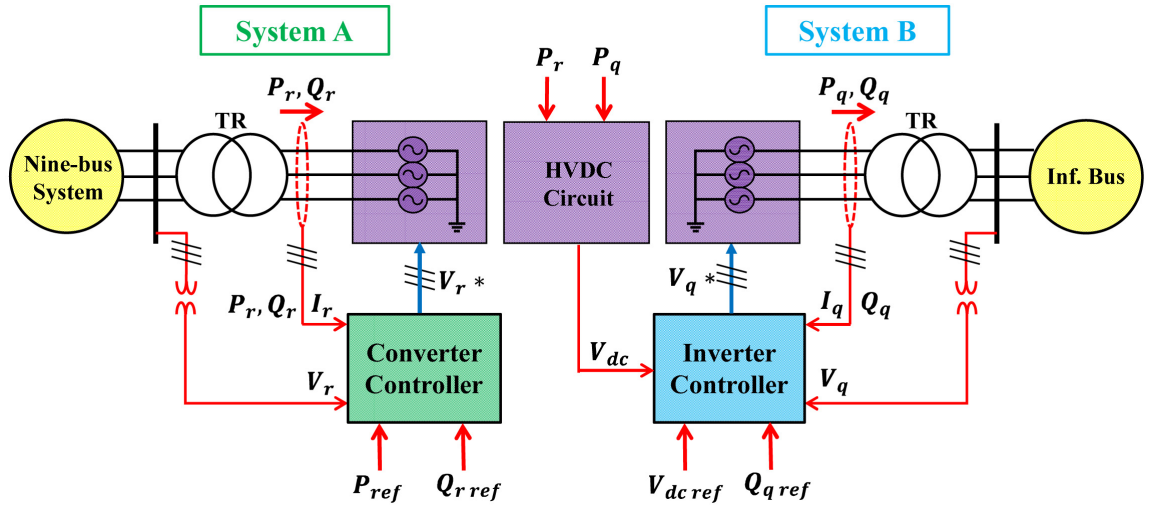

Figure 6. VSC-HVDC simple model.

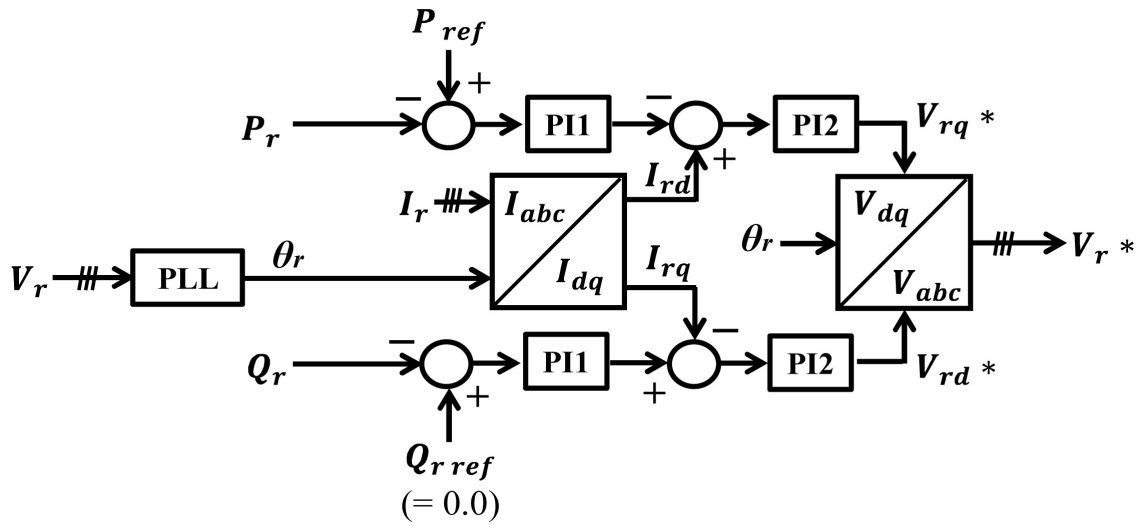

Figure 7. Converter control system.

of the HVDC line and reactive power output $Q_{q}$ of the inverter are controlled by the $\mathrm{d}$-axis and q-axis components. For this purpose, the d-axis and q-axis components $\left(V_{q d}^{*}, V_{q q}^{*}\right)$ of the voltage are obtained through the PI controller. Finally, the $\mathrm{d}$-axis and $\mathrm{q}$-axis voltages are converted to three-phase AC voltages. The parameters of PI controllers (PI3, PI4) are shown in Table 3. 


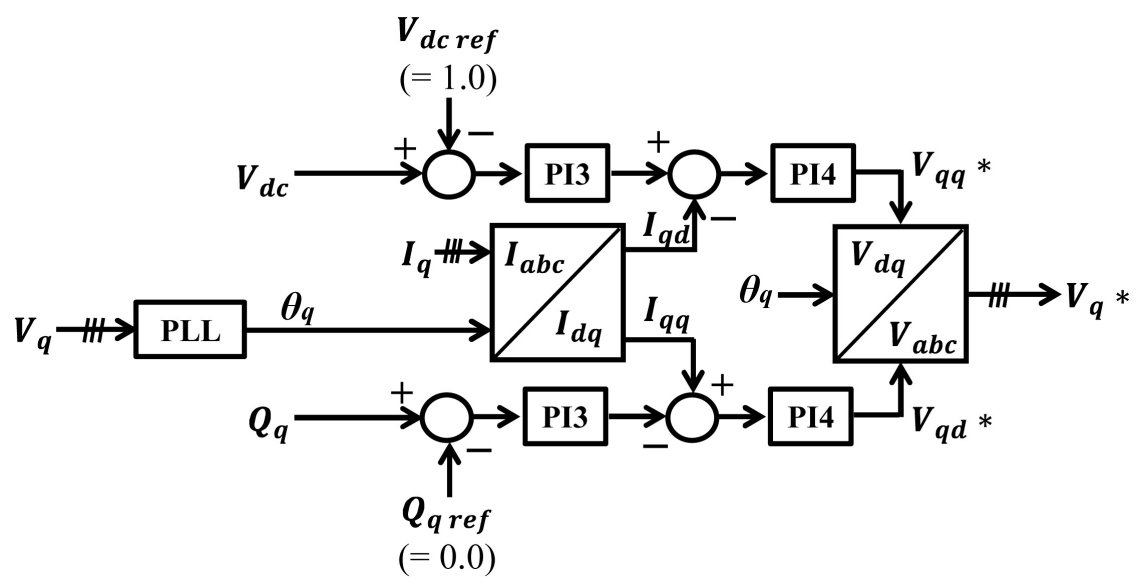

Figure 8. Inverter control system.

Table 3. Parameters of PI controller.

\begin{tabular}{ccccc}
\hline & PI1 & PI2 & PI3 & PI4 \\
\hline Proportional gain & 0.1 & 0.1 & 1.0 & 0.1 \\
Integral time constant & 0.01 & 1.0 & 0.1 & 1.0 \\
\hline
\end{tabular}

\subsection{DC-Link Model}

The DC-Link model is shown in Figure 9, in which the DC-link voltage is expressed by Equation (6) [7] [9].

$$
\mathrm{d} V_{d c} / \mathrm{d} t=\left(1 / V_{d c} C_{d c}\right)\left(P_{r}-P_{q}\right)
$$

where, $V_{d c}$ DC Voltage, $C_{d c}$ Capacitance of smoothing capacitor in the DC link $(50,000 \mu \mathrm{F}), P_{r}$ Active power of the converter, $P_{q}$ : Active power of the inverter. Rated voltage of the HVDC line is $250 \mathrm{kV}$.

\subsection{Proposed Methods for Frequency Control in HVDC Transmission Line}

\subsubsection{Frequency Band Control Using Notch Filter}

Firstly frequency characteristics of System A are analyzed in order to clarify the frequency band in which the synchronous generators and their frequency control systems in System A cannot suppress frequency fluctuations sufficiently. In order to perform the frequency characteristic analysis, System A of Figure 1 is expressed by using the simple frequency block model shown in Figure 10 [14] [15]. Figure 11 shows the result of frequency characteristics of System A, in which $\mathrm{X}$-axis denotes frequency of input power variation and $\mathrm{Y}$-axis denotes the maximum frequency deviation in System A. "No frequency control" in Figure 11 shows the result calculated from transfer function from output variations of WF and PV to frequency variations of System A, which is obtained from the frequency block model.

Next, in order to construct a control system for HVDC line, a notch filter has been designed. The role of the filter is to decrease the frequency components that the synchronous generators and their frequency control systems in System 


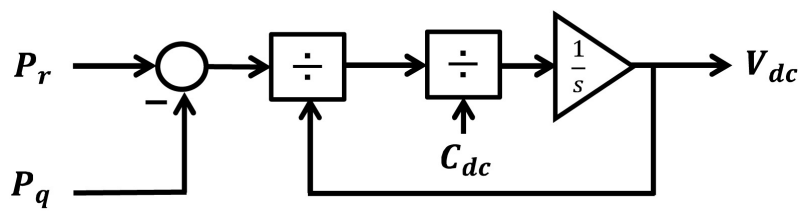

Figure 9. DC-Link control block.

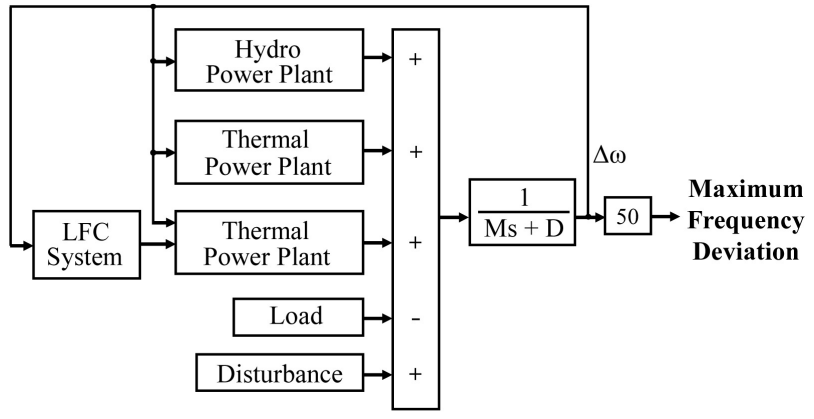

Figure 10. Simple frequency block model.

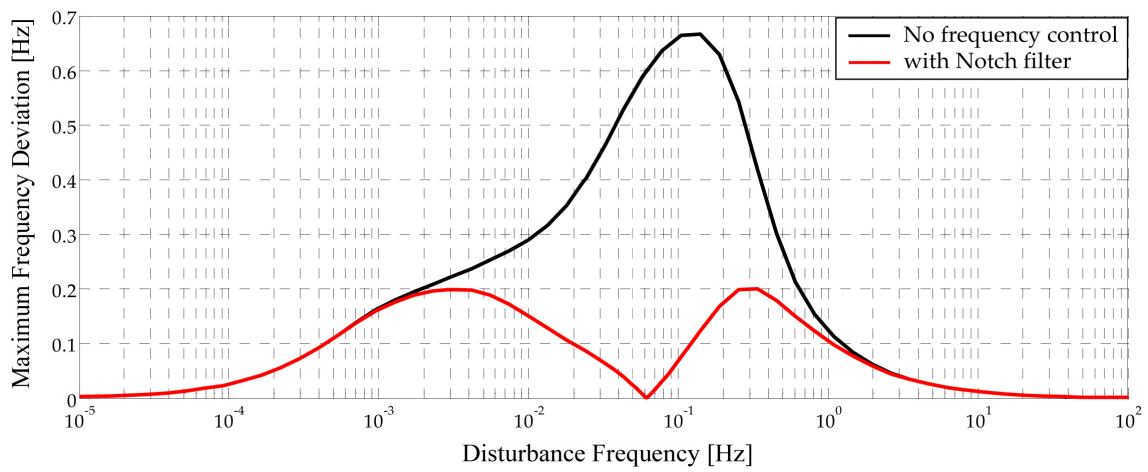

Figure 11. Frequency characteristics of System A.

A cannot suppress sufficiently. Since the permissible range of power system frequency deviation in Japan is, in general, within $\pm 0.2 \mathrm{~Hz}$, the filter is designed so that the maximum frequency deviation is equivalent to $0.2 \mathrm{~Hz}$. "with Notch filter" in Figure 11 are the results. In this paper, the transfer functions of the designed notch filter is shown in Equation (7), where $\zeta_{1}$ is damping coefficient, $\omega_{c l}$ is center angular frequency, and their values are set to $\zeta_{1}=4.9, \omega_{c 1}=0.387$ respectively.

$$
H(s)_{n o t c h}=\left(s^{2}+\omega_{c 1}^{2}\right) /\left(s^{2}+2 \zeta_{1} \omega_{c 1} s+\omega_{c 1}^{2}\right)
$$

Figure 12 shows a block diagram to determine reference output of HVDC transmission line, where $\Delta f$ is the frequency deviation in System A and $P_{r e f}$ is the reference for HVDC line power. In the case of the proposed method, by passing $\Delta f$ through the notch filter and subtracting the filter output from $\Delta f$, the fluctuating frequency components that cannot be suppressed sufficiently is obtained, and finally, by adding the steady state reference value for HVDC line power, $P_{D C 0}$ (=0.5 [p.u.] in this study), to it, $P_{\text {ref }}$ is determined. $P_{r e f}$ is limited within $P_{D C 0} \pm 0.1$ [p.u.] by using the hard limiter as shown in Figure 12 in order to suppress the 


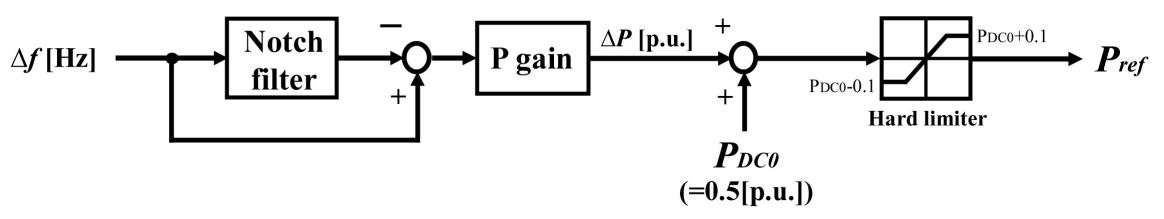

Figure 12. Block diagram to determine HVDC line output using notch filter.

fluctuations of HVDC line power. P gain in Figure 12 is set to $\% K_{G}=15.0$, which is the system constant of System A. The equation about the system constant $\% K_{G}$ is shown in Equation (8). $K_{G}$ is the amount of total generator output which needs to change the system frequency by $1[\mathrm{~Hz}]$.

$\% K_{G}=\left(K_{G} \times 100\right) /$ sum of the Rated Capacities of Parallel Generator

\subsubsection{Frequency Control Using Deadband}

Figure 13 shows a block diagram of the proposed frequency control with deadband [16] [17] for the HVDC line, where $P_{\text {ref }}$ denotes a reference for HVDC line power flow and it is determined according to the frequency deviation $\Delta f[\mathrm{~Hz}]$ of the main system (System A). In Figure 13, $\Delta P=0$ when $\Delta f[\mathrm{~Hz}]$ is less than the threshold value " $a$ " [Hz] in the deadband, and $\Delta f^{*} \mathrm{P}$ gain is sent to the adder when $\Delta f[\mathrm{~Hz}]$ is greater than the threshold value. Target value $P_{\text {ref }}$ of the HVDC line flow is calculated by adding $\Delta P$ to the steady state reference value, $P_{D C O}$ (= 0.5 [p.u.] in this study). $P_{\text {ref }}$ is limited within $P_{D C O} \pm 0.1$ [p.u.] by using the hard limiter as shown in Figure 13 also in this case. Therefore, HVDC line flow is composed of compensating component for the frequency fluctuations and the steady state reference. In Figure 14, the output image of the deadband is shown. The threshold value "a" of the deadband is set to $0.05[\mathrm{~Hz}]$ in this paper, and $\mathrm{P}$ gain is set to $\% K_{G}=15.0$, which is the system constant of System $\mathrm{A}$. The equation about the system constant $\% K_{G}$ is shown in Equation (8).

\section{Simulation Results}

To confirm the effectiveness of the proposed methods, simulation analyses for the model system of Figure 1 are performed on PSCAD/EMTDC software for the three cases; Case 1: No frequency control, Case 2: Frequency control with Notch filter in Figure 12, Case 3: Frequency control with Deadband shown in Figure 13. These 3 cases are shown in Table 4. The wind speed data shown in Figure 15 is input into the wind turbine model in the simulation analyses. This is real wind speed data measured in Hokkaido Island, Japan. The calculated output of wind turbine generator is shown in Figure 16. The PV output data shown in Figure 17 is used in the simulation analyses. This is also real PV data measured in Hokkaido Island, Japan. The total of this output of wind turbine generator and PV station is shown in Figure 18.

Simulation results of 3 cases are shown in Figure 19 and Figure 20. Figure 19 shows responses of System A frequency and it is seen the frequency variations exceed $\pm 0.2 \mathrm{~Hz}$ in Case 1 (No frequency control), but the frequency variations 


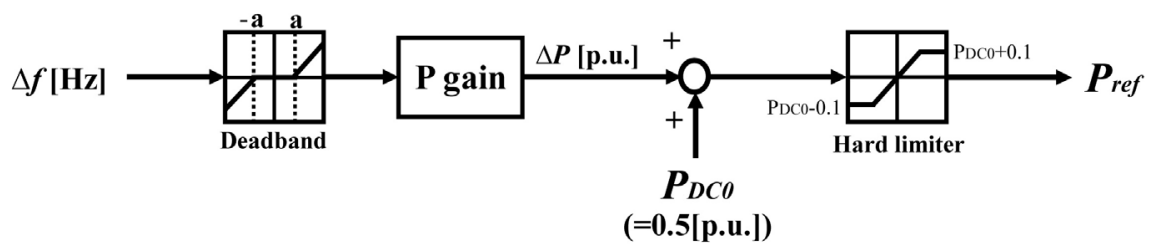

Figure 13. Block diagram to determine HVDC line output using deadband.

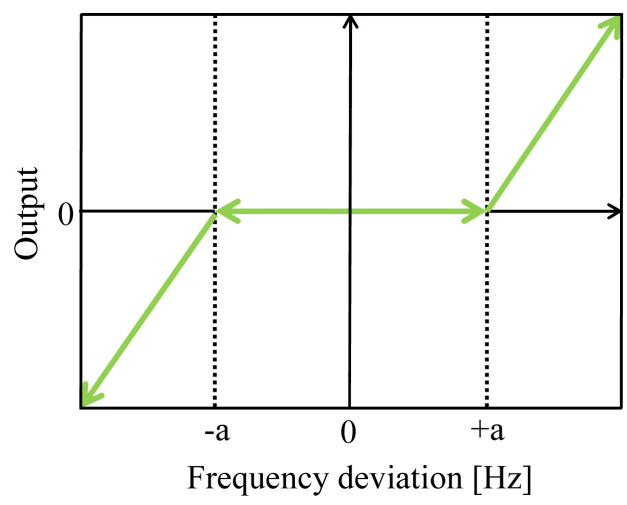

Figure 14. Output image in deadband.

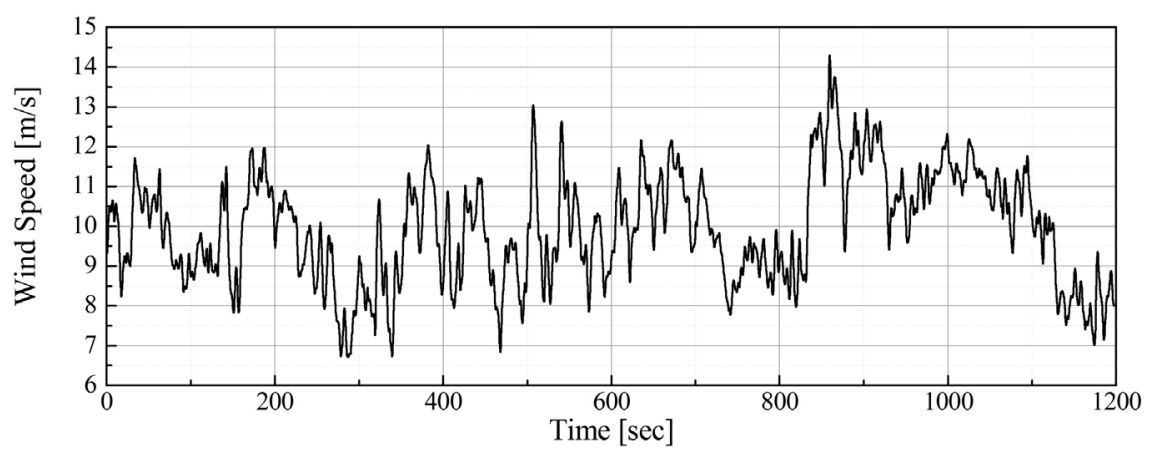

Figure 15. Wind speed data.

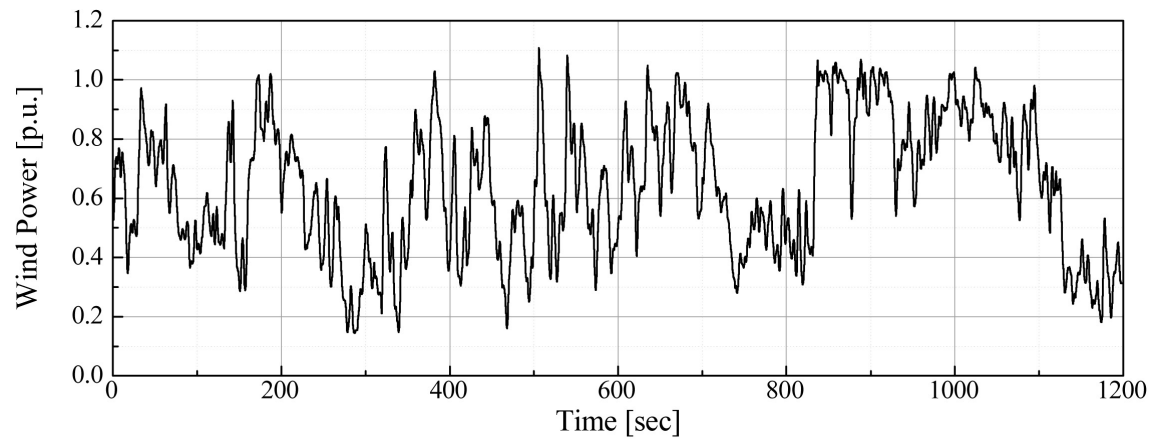

Figure 16. Output of wind power generator.

are well controlled in Case 2 (Frequency control with Notch filter) and Case 3 (Frequency control with Deadband). Figure 20 shows power flow of HVDC transmission line, from which it is seen that the fluctuations of the HVDC line power in Case 3 are much less than those in Case 2. Table 5 shows the maximum 


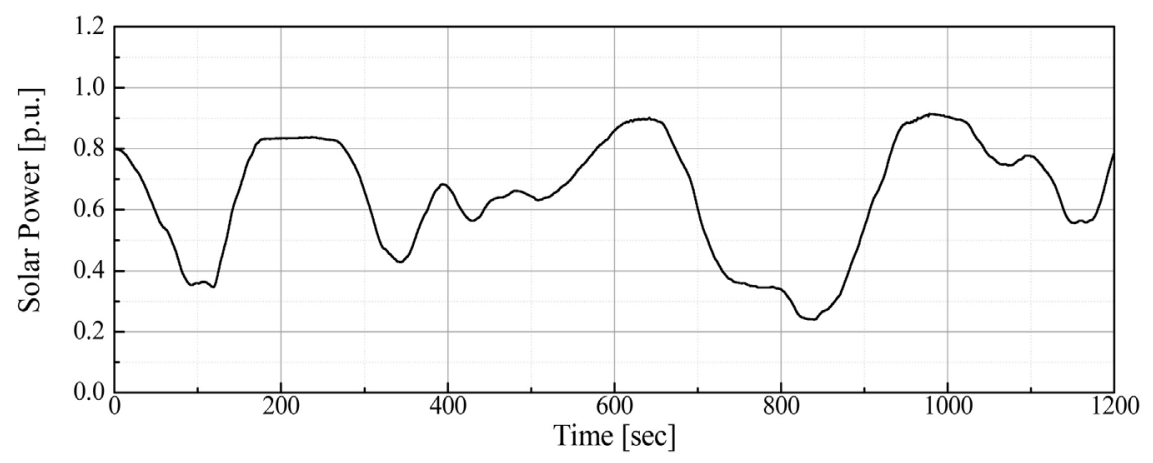

Figure 17. Output of PV station.

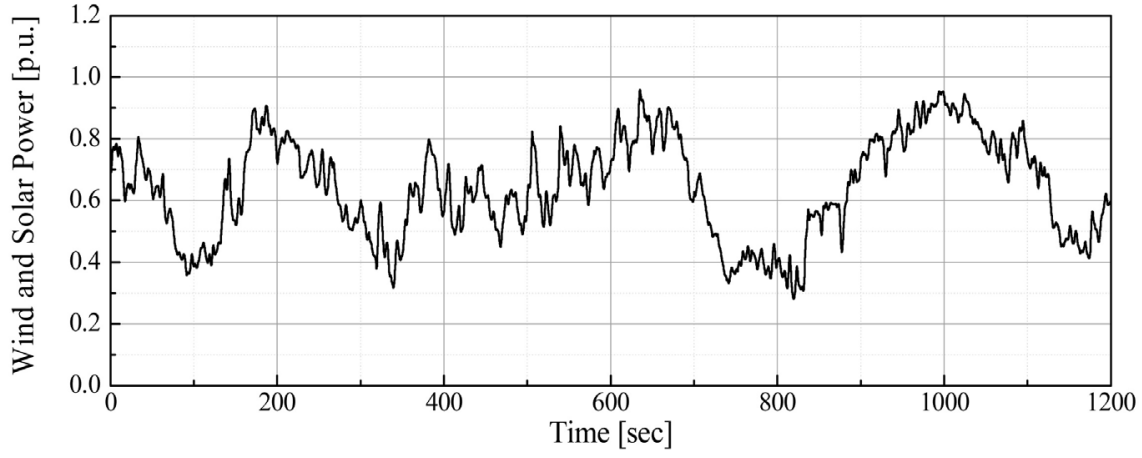

Figure 18. Total output of WF and PV.

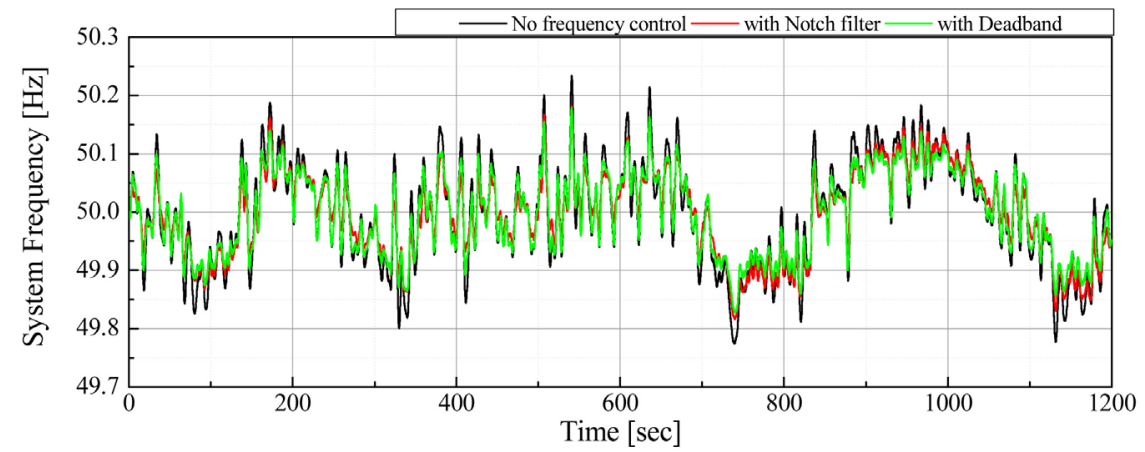

(a)

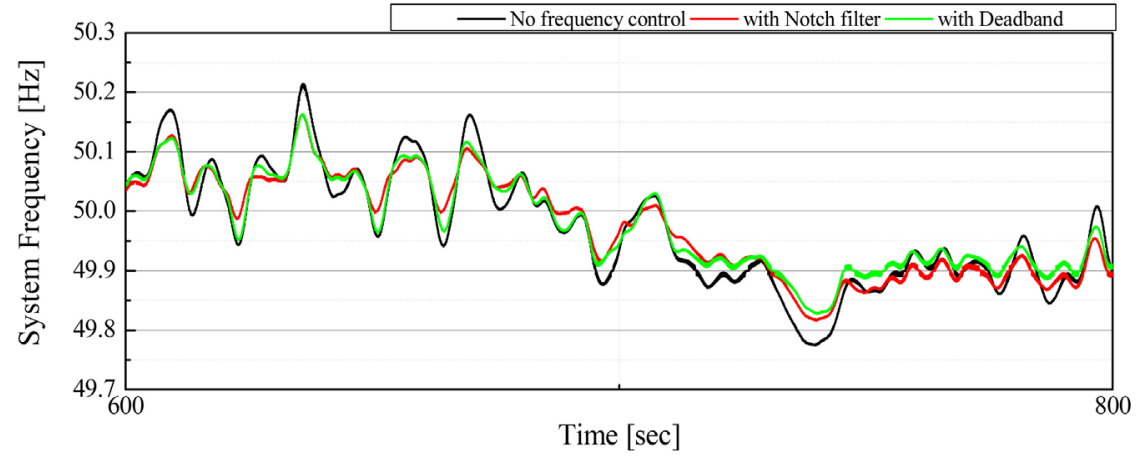

(b)

Figure 19. (a) Comparison of system frequency. (b) Comparison of system frequency (enlarged). 


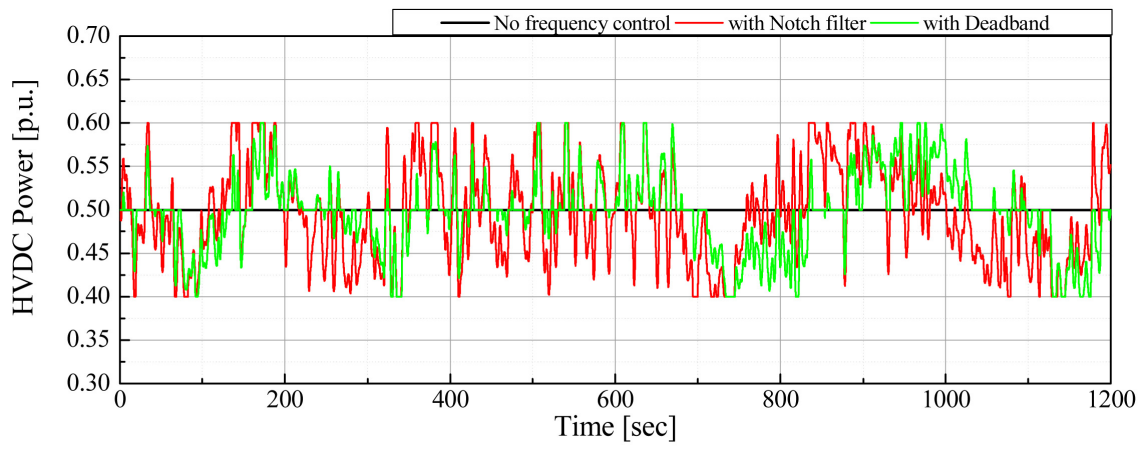

(a)

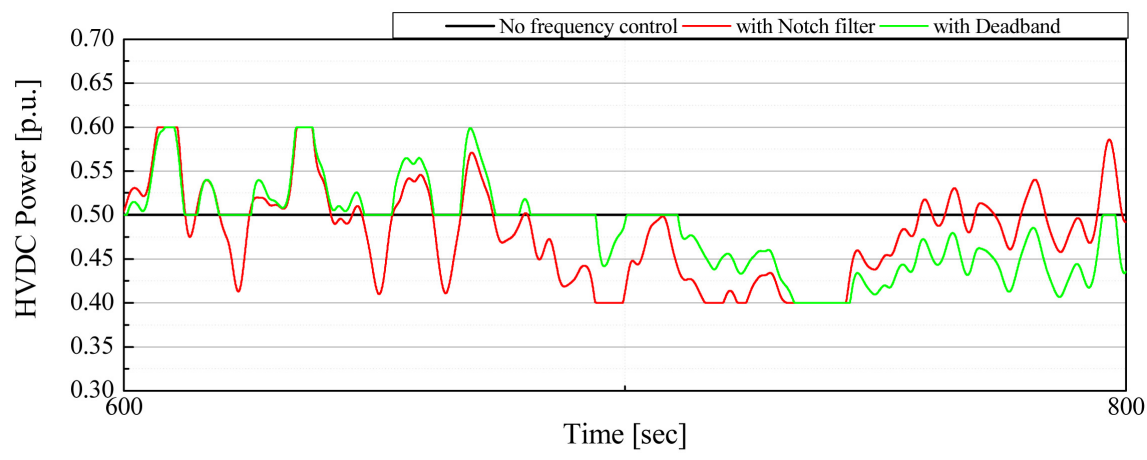

(b)

Figure 20. (a) Comparison of HVDC transmission power. (b) Comparison of HVDC transmission power (enlarged).

Table 4. Study cases.

\begin{tabular}{cc}
\hline Case & Description \\
\hline 1 & No frequency control \\
2 & (HVDC transmission power is set to 0.5 p.u.) \\
& Frequency control with Notch filter \\
3 & (HVDC transmission power is controlled within $0.5 \pm 0.1$ p.u.) \\
& Frequency control with Deadband \\
& (HVDC transmission power is controlled within $0.5 \pm 0.1$ p.u.)
\end{tabular}

Table 5. Maximum deviation and standard deviation of system frequency.

\begin{tabular}{cccc}
\hline & $\begin{array}{c}\text { Case 1 } \\
\text { (No Frequency } \\
\text { control })\end{array}$ & $\begin{array}{c}\text { Case 2 } \\
\text { (Frequency control } \\
\text { with Notch filter) }\end{array}$ & $\begin{array}{c}\text { Case 3 } \\
\text { (Frequency control } \\
\text { with Deadband) }\end{array}$ \\
\hline $\begin{array}{c}\text { Maximum Frequency } \\
\text { Deviation }+\Delta f[\mathrm{~Hz}]\end{array}$ & 0.234 & 0.182 & 0.179 \\
$\begin{array}{c}\text { Maximum Frequency } \\
\text { Deviation }-\Delta f[\mathrm{~Hz}]\end{array}$ & -0.225 & -0.184 & -0.172 \\
Standard Deviation $[\mathrm{Hz}]$ & 0.0805 & 0.0728 & 0.0704 \\
\hline
\end{tabular}

deviation and standard deviation of the system frequency fluctuations, from which it is also seen that the system frequency fluctuations can be suppressed effectively in Case 2 and Case 3. Table 6 shows the maximum deviation and 
Table 6. Maximum deviation and standard deviation of HVDC line power.

\begin{tabular}{cccc}
\hline & $\begin{array}{c}\text { Case 1 } \\
\text { (No Frequency } \\
\text { control) }\end{array}$ & $\begin{array}{c}\text { Case 2 } \\
\text { (Frequency control } \\
\text { with Notch filter) }\end{array}$ & $\begin{array}{c}\text { Case 3 } \\
\text { (Frequency control } \\
\text { with Deadband) }\end{array}$ \\
\hline $\begin{array}{c}\text { Maximum Deviation } \\
\text { of HVDC power } \\
+\Delta P_{\text {ref }} \text { [p.u.] }\end{array}$ & 0.0 & 0.100 & 0.100 \\
$\begin{array}{c}\text { Maximum Deviation } \\
\text { of HVDC power } \\
-\Delta P_{\text {ref }} \text { [p.u.] } \\
\text { Standard Deviation }\end{array}$ & 0.0 & -0.100 & -0.100 \\
of HVDC power [p.u.] & 0.0 & & 0.0438 \\
\hline
\end{tabular}

standard deviation of the HVDC line power, from which it is also seen that the HVDC power fluctuations can be suppressed effectively in Case 3 .

\section{Discussion}

In the simulation analysis of Section 3, two proposed methods for stabilizing the frequency fluctuations of system A have been analyzed. From Table 5, it is seen that the frequency control using the deadband (Case 3) can suppress the frequency fluctuations slightly more than the frequency control using the notch filter (Case 2). This is because, the frequency control based on the notch filter suppresses the frequency fluctuations just within $\pm 0.2 \mathrm{~Hz}$ while the control using deadband suppresses all components of the frequency fluctuations whenever the fluctuations become over the threshold value. On the other hand, it is seen from Table 6 that the standard deviation of the HVDC line power flow is less in the frequency control using the deadband (Case 3) than in the control using the notch filter (Case 2). This is because the HVDC line power in Case 2 always fluctuates while the HVDC line power in Case 3 does not so fluctuate as can be seen from Figure 20. HVDC line power control always activates in Case 2 but it activates in Case 3 only when the frequency fluctuations become over the threshold value. Therefore the HVDC line power flow fluctuations are less in Case 3 than Case 2. Considering these aspects, it is concluded that the frequency control using the deadband (Case 3) is superior to the frequency control using the notch filter (Case 2).

\section{Conclusion}

In order to suppress the frequency fluctuations in the power system with large amount of PV and WF installed, two methods of frequency control based on the power flow control of HVDC interconnection line are proposed in this paper, and their validity is examined through simulation analyses. As a result, it is shown that both methods can suppress the frequency fluctuations effectively. Considering the ability to suppress the system frequency fluctuations with fewer fluctuations in HVDC line power flow, however, it can be concluded that the 
frequency control using the deadband is superior to the frequency control using the notch filter. Therefore, this paper recommends the frequency control using the deadband for suppressing the frequency fluctuations in the power system with large amount of wind power generation and solar power generation. The proposed method can contribute to a design of frequency control system of power system which includes large amount of wind power generation and solar power generation and is connected to other power system through a HVDC interconnection line. The authors are planning to include the balancing control of the HVDC line into the proposed method.

\section{Acknowledgements}

This study was supported by the Grant-in-Aid for Scientific Research (B) from The Ministry of Education, Science, Sports and Culture of Japan.

\section{Conflicts of Interest}

The authors declare no conflicts of interest regarding the publication of this paper.

\section{References}

[1] Global Wind Energy Council (GWEC). (2015) Annual Market Update 2015, Global Wind Report. http://gwec.net/

[2] Renewable Energy Policy Network for the 21st Century (REN21). Renewables 2017 Global Status Report.

http://www.ren21.net/status-of-renewables/global-status-report/

[3] Liu, H. and Chen, Z. (2015) Contribution of VSC-HVDC to Frequency Regulation of Power Systems with Offshore Wind Generation. IEEE Transactions on Energy Conversion, 30, 918-926. https://doi.org/10.1109/TEC.2015.2417130

[4] Guan, M., Cheng, J., Wang, C., Hao, Q., Pan, W., Zhang, J. and Zheng, X. (2017) The Frequency Regulation Scheme of Interconnected Grids with VSC-HVDC Links. IEEE Transactions on Energy Conversion, 32, 864-872.

[5] Li, Y., Xu, Z., Østergaard, J. and Hill, D.J. (2017) Coordinated Control Strategy for Offshore Wind Farm Integration via VSC-HVDC for System Frequency Support. IEEE Transactions on Energy Conversion, 32, 843-856. https://doi.org/10.1109/TEC.2017.2663664

[6] Wang, L., Lin, C.-Y., Wu, H.-Y. and Prokhorov, A.V. (2017) Stability Analysis of a Microgrid System with a Hybrid Offshore Wind and Ocean Energy Farm Fed to a Power Grid Through an HVDC Link. IEEE Industry Applications Society, 54, 2012-2022. https://doi.org/10.1109/TIA.2017.2787126

[7] Jahan, E., Hazari, Md.R., Rosyadi, M., Umemura, A., Takahashi, R. and Tamura, J. (2017) Simplified Model of HVDC Transmission System Connecting Offshore Wind Farm to Onshore Grid. Proceedings of the IEEE PES PowerTech, Manchester, 18-22 June 2017, 1-6.

[8] Tada, K., Umemura, A., Takahashi, R., Tamura, J., Matsumura, Y., Yamaguchi, D., Kudo, H., Niiyama, M. and Take, Y. (2017) Frequency Control of Power System with Solar and Wind Power Stations Installed by Flow Control of HVDC Interconnection Line. Proceedings of the $201720^{\text {th }}$ International Conference on Electrical 
Machines and Systems (ICEMS), Sydney, 11-14 August 2017, 1-6.

[9] Sato, T., Umemura, A., Takahashi, R. and Tamura, J. (2017) Frequency Control of Power System with Large Scale Wind Farm Installed by Using HVDC Transmission System. Proceedings of the IEEE PES PowerTech, Manchester, 18-22 June 2017, 1-6.

[10] Anderson, P.M. and Found, A.A. (1944) Power System Control and Stability. IEEE Press, New York.

[11] Rosyadi, M., Umemura, A., Takahashi, R., Tamura, J., Uchiyama, N. and Ide, K. (2015) Simplified Model of Variable Speed Wind Turbine Generator for Dynamic Simulation Analysis. IEEJ Transactions on Power and Energy, 135, 538-549. https://doi.org/10.1541/ieejpes.135.538

[12] Liu, J., Rosyadi, M., Umemura, A., Takahashi, R. and Tamura, J. (2014) A Control Method of Permanent Magnet Wind Generators in Grid Connected Wind Farm to Damp Load Frequency Oscillation. IEEJ Transactions on Power and Energy, 134, 393-398. https://doi.org/10.1541/ieejpes.134.393

[13] Wasynczuk, O., Man, D.T. and Sullivan, J.P. (1981) Dynamic Behavior of a Class of Wind Turbine Generators during Random Wind Fluctuations. IEEE Power Engineering Review, PER-1, 47-48. https://doi.org/10.1109/MPER.1981.5511593

[14] Koiwa, K., Tahara, S., Tamura, J. and Liu, K.-Z. (2016) A Study on the Design of Battery Capacity and Control System Based on the Frequency Characteristics of Power System. IEEJ Transactions on Power and Energy, 136, 719-727.

https://doi.org/10.1541/ieejpes.136.719

[15] Tahara, S., Koiwa, K., Umemura, A., Takahashi, R. and Tamura, J. (2015) Frequency Characteristic Analysis of Power System and Its Application to Smoothing Control of Wind Farm Output. Proceedings of the 10 th International Conference on Ecological Vehicles and Renewable Energies (EVER), Monaco, 31 March-2 April 2015, 1-6.

[16] Ono, T. and Arai, J. (2012) Frequency Control with Dead Band Characteristic of Battery Energy Storage System for Power System Including Large Amount of Wind Power Generation. IEEJ Transactions on Power and Energy, 132, 709-717. https://doi.org/10.1541/ieejpes.132.709

[17] Yoshida, Y., Koiwa, K., Umemura, A., Takahashi, R. and Tamura, J. (2015) Power System Frequency Control with Dead Band by Using Kinetic Energy of Variable Speed Wind Power Generator. Proceedings of the 2015 IEEE Energy Conversion Congress and Exposition (ECCE), Montreal, 20-24 September 2015, 470-476. https://doi.org/10.1109/ECCE.2015.7309726 